\title{
Effect of precursor particle size and morphology on lithiation of $\mathrm{Ni}_{0.6} \mathrm{Mn}_{0.2} \mathrm{Co}_{0.2}(\mathrm{OH})_{2}$
}

\author{
Marianna Hietaniemi ${ }^{1,2}$ (D) Tao Hu$^{1}$ (D) $\cdot$ Juho Välikangas ${ }^{1,2} \cdot J^{2}$ anne Niittykoski ${ }^{3}$ Ulla Lassi ${ }^{1,2}$ (D)
}

Received: 7 December 2020 / Accepted: 2 July 2021 / Published online: 18 July 2021

(c) The Author(s) 2021

\begin{abstract}
In this paper, $\mathrm{Ni}_{0.6} \mathrm{Mn}_{0.2} \mathrm{Co}_{0.2}(\mathrm{OH})_{2}$ precursors with several different morphologies and particle sizes are mixed with $\mathrm{Li}_{2} \mathrm{CO}_{3}$ and heat treated for 5, 7.5 and $10 \mathrm{~h}$. The effects of the precursor properties on the degree of lithiation, electrochemical properties and volumetric capacities of lithiated product are compared. Based on the characterization results, a small $(3 \mu \mathrm{m})$, narrow span precursor can be lithiated in a short period of time $(5 \mathrm{~h})$ and has good initial discharge capacity $\left(185 \mathrm{~mA} \mathrm{~h} \mathrm{~g}^{-1}\right)$ and capacity retention ( $93 \%$ for 55 cycles). In contrast, a large wide-span precursor requires over $10 \mathrm{~h}$ for full lithiation. A highly porous precursor can be lithiated faster than traditional large wide-span materials, and has low cation mixing and good crystallinity. However, the volumetric energy density of porous material is low after lithiation compared to the other tested materials. Capacity retention after washing correlated with crystallographic properties of the sample.
\end{abstract}

\section{Graphic abstract}

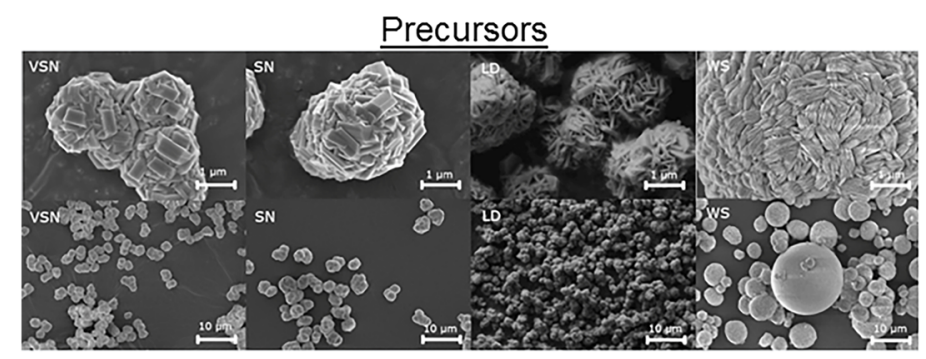

\section{Lithiated products}
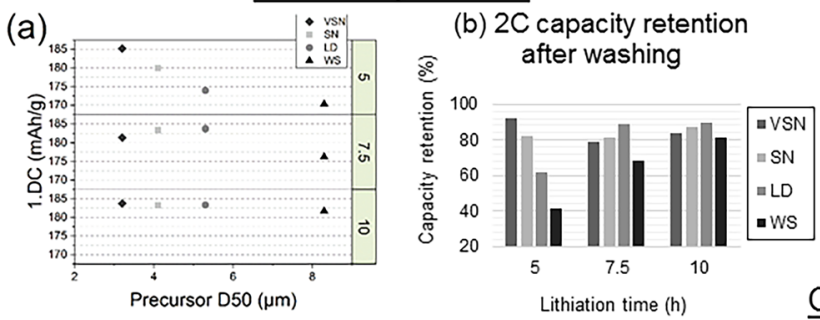

Cathode foils

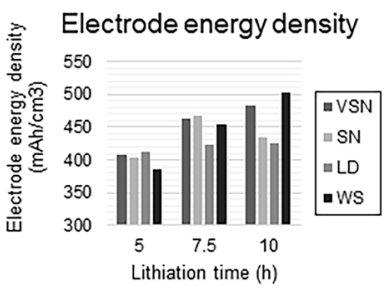

This article belongs to the Topical Collection: Batteries.

Extended author information available on the last page of the article 
Keywords Li-ion battery $\cdot \mathrm{LiNi}_{0.6} \mathrm{Mn}_{0.2} \mathrm{Co}_{0.2} \mathrm{O}_{2} \cdot$ Lithiation $\cdot$ Precursor effect $\cdot$ Electrochemical characterization

\section{Introduction}

Layered lithium-nickel-manganese-cobalt oxide (NMC) cathode materials are used in battery applications that require high energy density. They were first introduced by Ohzuku and Makimura [1] and later, researchers systematically investigated different nickel, cobalt and manganese ratios. $\mathrm{LiNi}_{0.6} \mathrm{Mn}_{0.2} \mathrm{Co}_{0.2} \mathrm{O}_{2}$ (NMC622) was one ratio of interest in Noh et al. [2]. By today's standards, NMC622 can almost be considered low-nickel because there is a constant push towards increasing the nickel content to $80 \%$ or higher in order to increase capacity. However, NMC622 is a very stable material compared to, for example, NMC811. It shows a lower amount of oxygen release from structure during heating, which improves safety [3], and it has considerably smaller variation in cell volume during cycling, which leads to less microcracking and longer cycle life [2].

Chemical composition is not the only way to affect electrochemical properties. To get the best possible performance out of a cathode material, particle size and morphology need to also be considered. In addition, successful lithiation is the most important factor defining the capacity of cathode materials. Precursors with different physical properties, such as particle size and porosity, have different requirements for lithiation time and temperature. In this work, we lithiated four precursors with different physical properties to determine how the precursor affects the optimal lithiation time.

Generally, the lithiation times used in the literature range from 12 to $24 \mathrm{~h}$. Cabelguen et al. [4] lithiated at $850-1000{ }^{\circ} \mathrm{C}$ for $24 \mathrm{~h}$ to obtain $\mathrm{LiNi}_{1} / 3 \mathrm{Mn}_{1} / 3 \mathrm{Co}_{1} / 3 \mathrm{O}_{2}$. Luo et al. [5] investigated the optimal lithiation conditions for NMC111 and concluded that $18 \mathrm{~h}$ at $850{ }^{\circ} \mathrm{C}$ was optimal. Their process included several steps, such as pre-calcination and pressing the material into pellets. Nie et al. [6] compared NMC523 precursors with different particle sizes (3, 6 and $9 \mu \mathrm{m})$. Their lithiation process, which was the same for all particle sizes, included preheating at $650{ }^{\circ} \mathrm{C}$ for $6 \mathrm{~h}$ and then $12 \mathrm{~h}$ in $800{ }^{\circ} \mathrm{C}$. Particles $3 \mu \mathrm{m}$ in size had the best layered structure after lithiation, and cation mixing was lower when particle size decreased.

Long lithiation time guarantees full lithiation but is not necessarily optimal for precursors with small particle sizes. If oxidation of precursor and lithium diffusion into the oxide structure has limited speed of reaction, it is logical to assume that small particles will be fully lithiated in shorter time. Long heating might also sinter small particles together. In addition to time, lithiation temperature is also important. Too low lithiation temperature will not guarantee fully lithiated structure, while too high lithiation temperature will cause cation mixing and structural changes that lower the materials electrochemical performance. Optimal lithiation temperature depends on the material's nickel content. Materials with high nickel content require lower lithiation temperatures. [2, 7, 8] Wang et al. [9] found that $850{ }^{\circ} \mathrm{C}$ was the optimal temperature to lithiate NMC622, although their starting precursor was nano scale (100-200 nm).

Excess amount of lithium is added during lithiation because it helps to prevent local lithium deficiencies and cation mixing. This is especially important for nickel rich materials. This also means that the over stoichiometric lithium needs to be considered in the manufacture process. The excess lithium is on the surface as $\mathrm{Li}_{2} \mathrm{O}, \mathrm{LiOH}$ and $\mathrm{Li}_{2} \mathrm{CO}_{3}$ $[10,11]$. Amount of $\mathrm{Li}_{2} \mathrm{CO}_{3}$ on the surface is related to storage conditions because $\mathrm{Li}_{2} \mathrm{O}$ will react to $\mathrm{LiOH}$ in the presence of moisture and $\mathrm{LiOH}$ reacts to $\mathrm{Li}_{2} \mathrm{CO}_{3}$. Because the extra lithium is not in the material structure, it will only do side reactions and not provide capacity. Lithium carbonate on the surface of the cathode material has been linked to gas formation in the cells [12]. In coin cells, gas formation can mostly be ignored because the volume of gas will be very small and coin cells have hard casing that keeps the electrodes pressed together. In commercial batteries gas formation can, however, cause bulging of the cell, which can break electrochemical contact. Residual surface lithium may also lower first cycle capacity [13], so to compare the material properties, a complete removal of excess surface lithium was deemed necessary. Exposure of cathode material to water will, however, lead to surface layer structural changes which form a resistance layer [14-16]. Because of this the cycling performance of water exposed sample will be worse than unwashed sample. Washing with ethanol does not cause similar structural changes [14]. However, because water is occasionally used in industry for washing, we wanted to compare if there is any difference in how the materials react to water washing.

Another variable that is rarely given attention in scientific articles, but is an important consideration for cathode materials, is volumetric capacity $\left(\mathrm{mA} \mathrm{h} \mathrm{cm}^{-3}\right)$. Porous materials have been studied for their improved lithium ion diffusion kinetics, which enable faster C-rates during charge and discharge [17]. In their review of porous lithium ion battery materials, $\mathrm{Vu}$ et al. [18] conclude that their porosity leads to low cathode volumetric capacity and needs to be compensated for somehow.

In addition to porosity, particle size distribution has an influence on final volumetric capacity and cycling stability. Zhang et al. [19] found that a 7:2:1 mixture of 9, 6 and $3 \mu \mathrm{m}$ particles provided better volumetric capacity (394.3 $\mathrm{mA} \mathrm{h} \mathrm{cm}{ }^{-3}$ with $1 \mathrm{C}$-rate charge/discharge) than any single particle size. They calculated volumetric capacity based on 
the tap density of the material and its specific gravimetric capacity $\left(\mathrm{mA} \mathrm{h} \mathrm{g}^{-1}\right)$. On the other hand, differences in particle size in cathode material might lead to uneven states of charge in different-sized particles, leading to either structural collapse in small particles that become over-charged or unutilized charge in large particles where lithium extraction is slower [20].

Cabelguen et al. [4] compared the tap densities of materials to calculate the volumetric energy density for several cathode materials with different morphology. They concluded that tap density might not accurately correspond to real packing in the electrode. Tap density is the optimal packing density of a material, and it depends on several factors, including how well the particles fit together. A material that is a blend of different-sized particles has higher tap density, because packing spheres of same size will inevitably leave empty space between particles. Therefore, using tap density to calculate a specific volumetric capacity for the active material does not necessarily correlate with final volumetric capacity of the cathode electrode, because the electrode is a mixture of active material, conductivity carbon and binder.

Loading is the mass of active cathode material per $\mathrm{cm}^{2}$ on cathode electrode. The used loading is sometimes very low in research samples, as low as $2-4 \mathrm{mg} \mathrm{cm}^{-2}$. The amount of loading is not standardized in any way and there are reasons why low loading might be good choice. It uses less sample, and the ratio of conductivity carbon can be higher which guarantees that lack of conductivity does not cause problems. Further, thin cathode allows accurate testing of how active material reacts to higher c-rates. [21] In our study, we use a larger loading $\left(10 \mathrm{mg} \mathrm{cm}^{-2}\right)$. This allows better accuracy and repeatability for electrode volumetric capacity estimation. Commercial loadings are around $20 \mathrm{mg} \mathrm{cm}^{-2}$ or even higher by optimizing particle size of active material and other components, and the calendering pressure. [22]

Optimization of production chain from precursors to battery cell production requires the knowledge of how precursors with different size and morphology react to lithiation conditions. When precursors are compared, it might make sense to judge materials on the lithiation process they require, and the final volumetric capacity of cathode electrode, not specific capacity of the active material. This study also highlights the importance of considering lithiation behaviour when comparing the electrochemical performance of different cathode active materials. Differences in electrochemical performance can arise just from precursor size and porosity.

\section{Experimental}

\subsection{Precursors}

NMC622 precursors with varying morphology and particle size were obtained from Umicore Finland. The tap density, BET surface area, particle size and $\mathrm{Na}$ and $\mathrm{S}$ impurity analysis results for precursors are presented in Table 1, and field electron scanning microscope (FESEM) images are presented in Fig. 1. The VSN (very small and narrow span) and SN (small and narrow span) precursors are small, dense particles with a narrow size distribution. Both have similar morphologies and amounts of impurities, but they have slightly different average particle sizes (D50). The LD (lowdensity) precursor has low tap density because of voids in the primary particle packing. The WS (wide-span) precursor represents a common wide-span precursor material. It has the widest particle size distribution, the largest particle size and the highest tap density of compared precursors.

\subsection{Lithiation}

The precursors were mixed with $\mathrm{Li}_{2} \mathrm{CO}_{3}$ (Rockwood 99\%) in an IKA A 11 Basic Analytical Mill. The amount of lithium we used was $5 \%$ over the stoichiometric lithium ratio (i.e. molar ratio of lithium to metal is 1). Mixed materials were lithiated in a chemical vapour deposition oven (Firstnano EasyTube $3000 \mathrm{EXT}$ ) with $1 \mathrm{~L} \mathrm{~min}^{-1}$ oxygen gas flow (Aga $99 \%$ ) at $850^{\circ} \mathrm{C}$ for $5,7.5$ and $10 \mathrm{~h}$. The lithiation time does not include heating ramp time, only the hold time at the set
Table 1 Precursor material properties

\begin{tabular}{llllllr}
\hline Name & $\begin{array}{l}\text { Tap density }(\mathrm{g} \\
\left.\mathrm{cm}^{-3}\right)\end{array}$ & $\begin{array}{l}\text { BET Surface area } \\
\left(\mathrm{m}^{2} \mathrm{~g}^{-1}\right)\end{array}$ & D50 $(\mu \mathrm{m})$ & Span & $\mathrm{Na}\left(\mathrm{g} \mathrm{t}^{-1}\right)$ & ${\mathrm{S}\left(\mathrm{g} \mathrm{t}^{-1}\right)}$ \\
\hline $\mathrm{VSN}^{\mathrm{a}}$ & 2.02 & 5.40 & 3.2 & 0.59 & 89 & 535 \\
$\mathrm{SN}^{\mathrm{b}}$ & 2.13 & 5.60 & 4.1 & 0.49 & 53 & 416 \\
$\mathrm{LD}^{\mathrm{c}}$ & 1.18 & 18.5 & 5.3 & 0.79 & 115 & 969 \\
$\mathrm{WS}^{\mathrm{d}}$ & 2.23 & 3.2 & 8.3 & 1.67 & 140 & 1255 \\
\hline
\end{tabular}

${ }^{a}$ Very small and narrow

${ }^{\mathrm{b}}$ Small and narrow

${ }^{c}$ Low density

${ }^{\mathrm{d}}$ Wide-span 


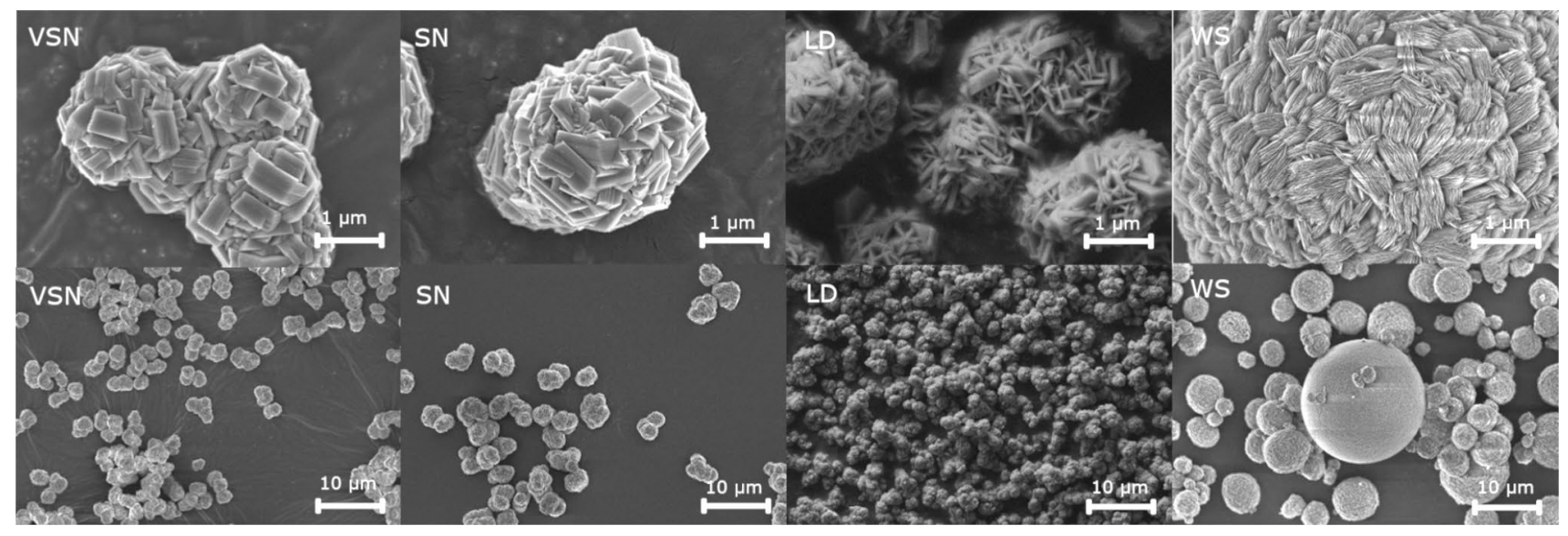

Fig. 1 FESEM of VSN, SN, LD and WS precursors with 50,000× magnification and 5,000× magnification

temperature. The heating ramp was $5{ }^{\circ} \mathrm{C} \mathrm{min}-1$ in all lithiations. Lithiation temperature of $850^{\circ} \mathrm{C}$ was chosen based on Wang et al. [9] and our own unpublished data showing good capacity for NMC622 in this temperature.

\subsection{Washing}

After lithiation, all samples were washed with water to remove excess lithium. Washing was done in order to determine how much lithium was in the structure. Samples were washed by strongly mixing the solid material for $10 \mathrm{~min}$ in deionised water with a magnetic stirrer. The ratio of sample to water was 4:100 to ensure that all lithium carbonate was dissolved. After the washed samples were filtered, the solid material on the filter paper was washed with a small amount of water, and samples were dried overnight in a vacuum oven at $190{ }^{\circ} \mathrm{C}$. The electrochemical properties for both washed and unwashed lithiated samples were tested in coin cells.

\subsection{Analysis of precursors and lithiated materials}

Particle sizes were measured with a Malvern Mastersizer 3000 with an attached Hydro EV sample dispersion unit. The refractive index and absorption index values used were 1.7 and 0.006 , respectively, for the precursors and 3 and 0.02 , respectively, for the lithiated materials.

The transition metal and $\mathrm{Li}$ contents were measured from dissolved samples by ICP-OES (Horiba Ultima Expert). Microwave digestion was used for total dissolution of these samples without any leaching residue. This was done based on EPA3051A standard using nitric acid: hydrochloric acid with the ratio of 3:1 as solvent. XRD was measured with a Rigaku SmartLab $9 \mathrm{~kW}$ X-ray diffractometer using Co as a source at $40 \mathrm{kV}, 135 \mathrm{~mA}$. Diffractograms were collected in the $2 \theta$ range of $5-120^{\circ}$ at $0.01^{\circ}$ intervals and a scan speed of $4.06 \mathrm{deg} \mathrm{min}^{-1}$. The software for analysis was PDXL2, which is included with the XRD device. The peaks were identified based on International Centre for Diffraction Data (ICDD PDF-4 + 2020). The crystallite sizes, anisotropy and distribution were computed using Rigaku PDXL2 analysis package. Whole powder pattern fitting (WPPF) was used with decomposition, least-square Pawley method. [23] Peak shape was modelled using the fundamental parameter (FP) method with continuous scan and the Cheary-Coelho axial model using experimental geometry and optics. The crystallite shape is refined as ellipsoidal model with lognormal distribution used as free parameters for iterative refinement. The method had been tested and proven to agree with transmission electron microscope (TEM) measurement of $\mathrm{SnO}_{2}$ crystallites.

The microstructure shown in field emission scanning electron microscope (FESEM) images were obtained using a Zeiss Sigma FESEM at the Centre for Material Analysis in the University of Oulu operated at $5 \mathrm{kV}$.

\subsection{Electrochemical testing}

All electrodes and coin cells were prepared in a dry room. Coin cell type was 2016. A cathode slurry was made using $4 \%$ polyvinylidene fluoride (Kureha \#1100) as binder, $4 \%$ conductivity carbon (Timcal Super C65) and 92\% active material and 1-methyl-2-pyrrolidinone (Alfa Aesar anhydrous $99.5 \%$ ) as a solvent. The ratio of solid material to solvent in the slurry could not be kept constant, because of the very different particle sizes of the samples. Smaller particle sizes result in a slurry with higher viscosity if no extra solvent is added, which leads to thicker electrode and has a clear effect on electrochemical properties. Instead, the loading (mass of active material per $\mathrm{cm}^{2}$ ) was kept as close to $10 \mathrm{mg} \mathrm{cm}^{-2}$ as possible.

The cathode slurry was spread on aluminium foil with an MTI AFA-III automatic film coater using a $100 \mu \mathrm{m}$ spreader 
bit. Then it was dried on a hot plate under a fume hood at $50{ }^{\circ} \mathrm{C}$ for $2 \mathrm{~h}$ and finally at vacuum oven at $120^{\circ} \mathrm{C}$ overnight. The cathode electrode was calendered three times with a rolling press (MTI Hot Rolls Press HR-02) before coin cell assembly. After calendering three times the cathode thickness no longer changed. Two coin cells were assembled from each sample cathode electrode, with metallic lithium (Alfa Aesar 99.9\% $0.75 \mathrm{~mm}$ foil) serving as the anode and $1 \mathrm{M} \mathrm{LiPF}_{6}$ (Novolyte Technologies) in 1:1:1 ethylene carbonate-diethyl carbonate-dimethyl carbonate serving as the electrolyte (ethylene carbonate Sigma-Aldrich anhydrous 99\%, diethyl carbonate Sigma-Aldrich anhydrous 99\%, dimethyl carbonate Novolyte Technologies $\geq 99 \%$ sealed under nitrogen). The cathode electrodes were cut to size using a cutting press with a set diameter of $14 \mathrm{~mm}$. Each cut cathode electrode was weighed, and the thickness was measured using a micrometre screw. Cell information can be found as supplementary data (S1). A Maccor series 4000 battery tester was used for electrochemical analysis. Cells were cycled between 3.0 and $4.3 \mathrm{~V}$ for 60 cycles at $25^{\circ} \mathrm{C}$. See Table 2 for the $\mathrm{C}$-rates that were used. The theoretical capacity used to calculate the $\mathrm{C}$-rate was $160 \mathrm{~mA} \mathrm{~h} \mathrm{~g}^{-1}$.

\section{Resultsand discussion}

\subsection{Effectof precursor on optimal lithiation time}

SEM images of the lithiated products are shown in Fig. 2. The only precursor that outwardly exhibited a significant change from precursor to lithiated product is $\mathrm{LD}$, which goes from having empty space in the precursor structure to being a lumpy uneven lithiated product. Other precursors maintain their appearance through lithiation. Morphology was not much affected by the lithiation time at this temperature.

The lithium molar amount divided by the transition metal molar amount $(\mathrm{Li} / \mathrm{Me})$ as a function of lithiation time after washing is shown in Fig. 3 for all samples. As shown, the precursor has a big impact on how quickly lithium is intercalated to cathode structure during lithiation. In particular, after lithiation for $5 \mathrm{~h}, \mathrm{VSN}$ and $\mathrm{SN}$ were lithiated close to the stoichiometric ratio, while LD and WS lack lithium (Li/Me around 0.93). Counterintuitively, VSN and SN lithiated for $5 \mathrm{~h}$, achieved more complete lithiation than when the lithiation time was longer. The reason for this behaviour is not clear.

When lithiation time is increased to 7.5 and $10 \mathrm{~h}, \mathrm{LD}$ has $\mathrm{Li} / \mathrm{Me}$ ratio closest to stoichiometric ratio (0.98 and 0.99). This indicates that the loose packing of primary particles in this precursor has a beneficial effect on lithium penetration of the structure, as has been previously reported for porous materials [17]. The trends for all samples indicate that increasing lithiation time over $10 \mathrm{~h}$ could slightly improve the Li/Me ratio, especially for WS, which at best has a $\mathrm{Li}$ / Me ratio of about 0.97 .

The Li/Me results measured from lithiated samples without washing matched the amount that was added to the precursor before lithiation so there was no significant lithium loss due to vaporization. Our lithium excess was also high so lithium loss in this way would is not significant factor in lithiation.

Differences in degree of lithiation (seen in $\mathrm{Li} / \mathrm{Me}$ ) are supported by the XRD results. The XRD patterns of lithiated samples are attached as supplementary data (S2) and showed no impurity phases. All samples had clear peak splitting of $(006) /(102)$ and $(108) /(110)$ caused by a well-defined $\alpha-\mathrm{NaFeO}_{2}$ structure (i.e. an ordered hexagonal structure) [24, 25].

The values of $\mathrm{c} / 3 \mathrm{a}$ and the (003)/(104) peak integrated intensity ratio are commonly considered to be indicators of cation mixing. An ideal cubic close packed lattice would have a c/3a ratio of 1.633 , with higher ratio indicating higher ordering and less cation mixing [26]. Values for the a-axis, $\mathrm{c}$-axis and $\mathrm{c} / 3 \mathrm{a}$ are presented in Fig. 4. The trend of $\mathrm{c} / 3 \mathrm{a}$ is almost identical to the measured lithium amount in the sample after washing (Fig. 3). VSN and SN show the same $\mathrm{V}$-shaped behaviour when lithiation time is increased in $\mathrm{c} / 3 \mathrm{a}$ as was seen in $\mathrm{Li} / \mathrm{Me}$. This could be explained by the fact that cation mixing is increased when the structure is lithium poor (Ni can take Li position) $[27,28]$ or the fact that $\mathrm{c} / 3 \mathrm{a}$ correlates more strongly with lithium amount in the structure than cation mixing. There will always be some amount of cation mixing, but when examining NMC111, Zhang et al. [28] found that amounts less than $2 \%$ do not affect electrochemical performance of the cell.

The $(003) /(104)$ ratio presented in Fig. $4 d$ is also commonly used as indicator of cation mixing, with higher value meaning lower amount of cation mixing. The (003) peak, which is the transition metal plane, will have lower intensity when there is lithium in transition metal places, and (104) peak, which is a plane crossing Li layer and transition metal oxide layer, will have higher intensity when there is transition metal in lithium places [29]. The $(003) /(104)$ ratio mostly agrees with $\mathrm{c} / 3 \mathrm{a}$, but there are some differences. For VSN behaviour is V-shaped like c/3a and sample lithiated for $5 \mathrm{~h}$ has highest ratio among all samples. LD has the highest ratio in 7.5 and $10 \mathrm{~h}$ lithiations. For SN,
Table 2 Coin cell testing programme

\begin{tabular}{llllllllll}
\hline Cycle number & 1 & 2 & 3 & 4 & 5 & $6-29$ & 30 & $31-59$ & 60 \\
\hline Charge C-rate & 0.1 & 0.2 & 0.2 & 0.2 & 0.2 & 0.2 & 0.2 & 0.2 & 0.2 \\
Discharge C-rate & 0.1 & 0.2 & 1 & 2 & 4 & 2 & 0.2 & 2 & 0.2 \\
\hline
\end{tabular}




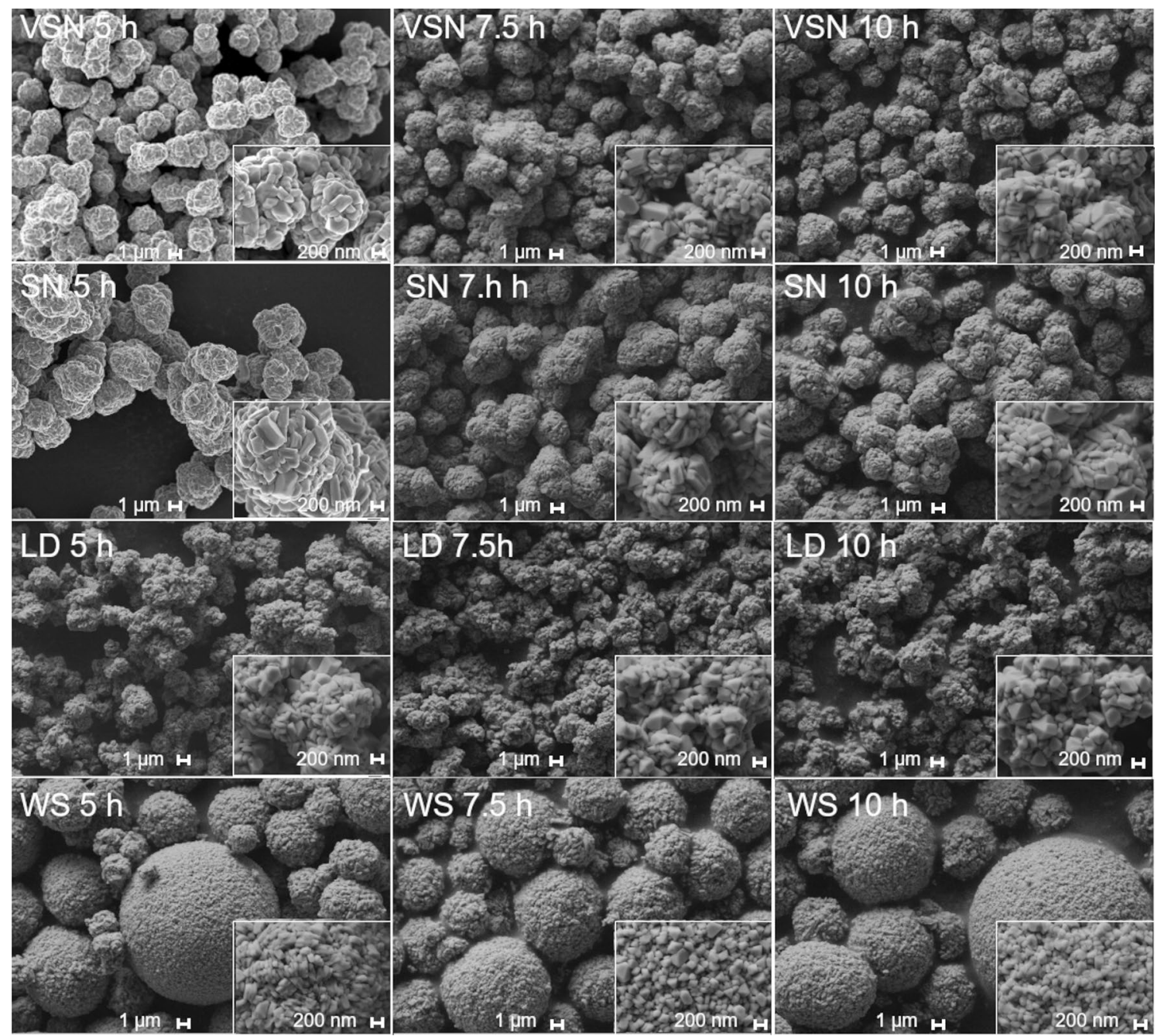

Fig. 2 SEM images of overall morphology and a close-up of the surface of VSN, SN, LD and WS lithiated at $850{ }^{\circ} \mathrm{C}$ for $5 \mathrm{~h}, 7.5$ and $10 \mathrm{~h}$

however, the ratio $(003) /(104)$ is lower when lithiation time is increased. According to common sense, SN and VSN should behave similarly because they have very similar properties (Table 1). This situation could be explained by the crystallite sizes presented in Fig. 4. The crystallite size after lithiation is quite large for VSN compared to SN. As shown in Fig. 4e, crystallite size is relatively unaffected by lithiation time, except for LD, which exhibits a clear growing trend. Figure $4 \mathrm{f}$ presents the full width at half maximum (FWHM) for the (003) peak, which is used as indicator of crystallinity because uniform crystal structure causes sharp peaks. LD achieves the best crystallinity and is more affected by lithiation time than the other precursors. In other samples, crystallinity is also improved by longer lithiation time, but the effect is less dramatic.

Figure 5 shows the first cycle discharge capacity and Li/ $\mathrm{Me}$ in relation to the precursor D50 for different lithiation times. The dependence of $\mathrm{Li} / \mathrm{Me}$ and the first cycle discharge capacity on precursor particle size is very linear after lithiation for $5 \mathrm{~h}$, meaning that the larger the particle size, the longer it takes to complete lithiation. Lithiation time of $7.5 \mathrm{~h}$ seems to be enough for the three smallest precursors, but not for WS. After $10 \mathrm{~h}$, the differences have mostly disappeared.

First cycle discharge capacity is lower in samples that are far from the stoichiometric lithium amount. The best initial capacity ( $185 \mathrm{~mA} \mathrm{~h} \mathrm{~g}^{-1}$ ) was measured from sample that seemed to be slightly over-lithiated. Samples that are close to the stoichiometric $\mathrm{Li} / \mathrm{Me}$ ratio have initial capacity close to each other regardless of the precursor or lithiation time that is used. Thus, $185 \mathrm{~mA} \mathrm{~h} \mathrm{~g}^{-1}$ can be tentatively presumed to be the maximum initial capacity for this material (regardless of morphology) in these testing conditions. Presumably, longer lithiation time would only raise the other materials to this level. Noh et al. [2] found that NMC622 had an initial capacity of $187 \mathrm{~mA} \mathrm{~h} \mathrm{~g}^{-1}$, which is compatible with our results. 


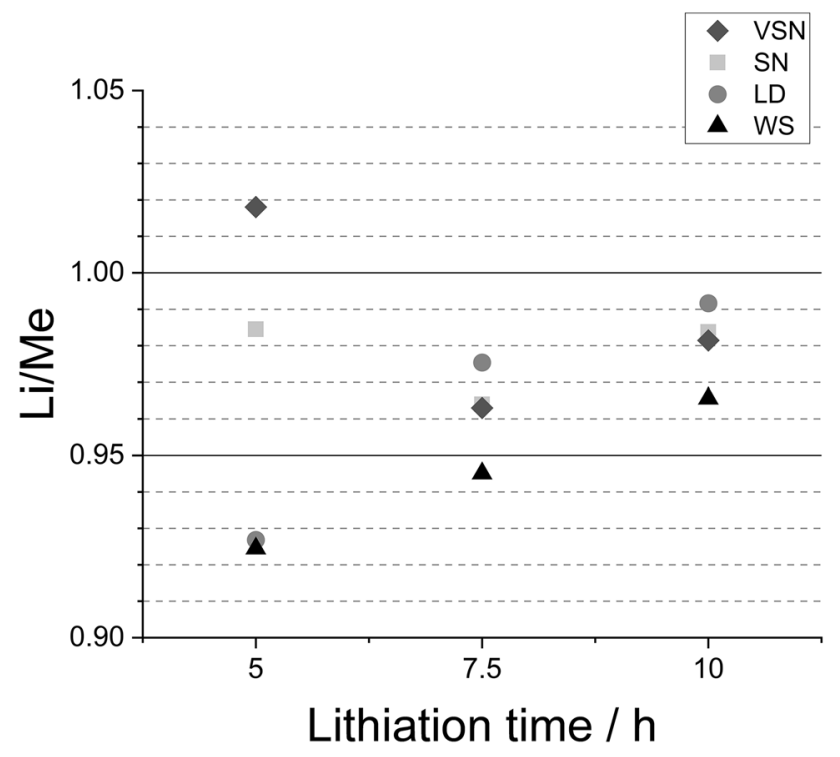

Fig. 3 Ratio of lithium to transition metal (measured from lithiated samples by ICP-OES after washing away water-soluble lithium residues) as a function of lithiation time

\subsection{Effect of precursor on capacity retention and C-rate capability}

The capacity retention of materials was tested for unwashed samples and after washing, and the results are presented in Fig. 6. Figure 7 shows the capacity during coin cell cycling for washed samples, with two cells from each sample shown. Voltage profiles are added as supplementary data (S3-4). No significant differences were seen in voltage profiles between the samples. Figures of capacities in different C-rates are presented as supplementary material (S5-6). Capacity in higher C-rates follows similar trend as first cycle capacity. In samples lithiated for $10 \mathrm{~h}$ the $4 \mathrm{C}$ capacity correlates with particle size, smallest VSN has $4 \mathrm{C}$ capacity around $157 \mathrm{~mA}$ $\mathrm{h} \mathrm{g}^{-1}$, while largest WS has $4 \mathrm{C}$ capacity of $140 \mathrm{~mA} \mathrm{~h} \mathrm{~g}^{-1}$. For VSN $4 \mathrm{C}$ capacity is unchanged by lithiation time (157 $\left.\mathrm{mA} \mathrm{h} \mathrm{g}^{-1}\right)$ and SN has only small variation $(\sim 145-154 \mathrm{~h}$ $\mathrm{g}^{-1}$ ). The larger particles lithiated for short time (LD $5 \mathrm{~h}$ and WS 5 and $7.5 \mathrm{~h}$ ) show clearly lower $4 \mathrm{C}$ capacities, likely due to insufficiently lithiated structure. WS $5 \mathrm{~h}$ has the lowest capacity at $4 \mathrm{C}$, only $112 \mathrm{~mA} \mathrm{~h} \mathrm{~g}^{-1}$. Other poorly lithiated samples also have low $4 \mathrm{C}$ capacity.

After cycling for 55 cycles using $0.2 \mathrm{C}$ charge and $2 \mathrm{C}$ discharge, the unwashed samples lithiated for $5 \mathrm{~h}$ had clear differences in capacity retention. VSN had the highest capacity retention (95\%) and WS the lowest capacity retention (85\%). In samples lithiated for $10 \mathrm{~h}$ the differences in cycle retention have almost completely disappeared and all samples have capacity retention of around $94 \%$. In washed samples lithiated for $5 \mathrm{~h}$, the differences in capacity retention are much more pronounced than in unwashed samples. VSN still has highest capacity retention (92\%) and WS the lowest $(41 \%)$. In washed samples with longer lithiation time, the capacity retention is improved for all samples except for VSN and the differences between samples remain larger than in unwashed samples. In samples lithiated for $10 \mathrm{~h} \mathrm{LD}$ has the highest capacity retention (89\%), while WS has the lowest (82\%). Based on the results, capacity retention seems to correlate with precursor particle size in the same way first cycle capacity does (Fig. 5). Smallest sample VSN has good capacity retention even after $5 \mathrm{~h}$ lithiation, while retention of larger samples is lower. After longer lithiation the differences disappear. This is most likely because the smallest precursor was fully lithiated in $5 \mathrm{~h}$, while precursors with larger particle size required longer time for complete oxidation and lithiation of the structure.

In washed samples, LD lithiated for 7.5 and $10 \mathrm{~h}$ stands out as having clearly better capacity retention than other samples. Water having detrimental effect on the cathode surface structure has been shown to be the cause for decreased cycle retention after washing. [14-16] It is logical to assume that materials resistance to the effects caused by washing is related to the materials surface area and how deep the water can penetrate inside the particles. According to XRD results (Fig. 4) LD lithiated for $10 \mathrm{~h}$ has the largest crystallite size, lowest FWHM which indicates uniform crystallographic structure, and one of the highest (003)/(104) ratios which indicates low amount of cation mixing. This also seems to correlate with Li/Me measured from the samples (Fig. 3). Based on these results material with uniform structure and large crystallite size has better resistance to washing, and this kind of material was produced by lithiating precursor with low density and porous surface (LD).

We did not perform surface area measurements for these samples, but typically lithiated cathode materials have very low surface area $\left(\sim 1 \mathrm{~m}^{2} \mathrm{~g}^{-1}\right)$ and the differences are very small. Li et al. [30] used Brunauer-Emmett-Teller method to measure the surface area of single-crystal cathode material and polycrystalline cathode material and concluded that there was no difference between the samples. Our samples look very similar to each other in SEM images, so to detect any difference a method dedicated for very low surface areas would be necessary.

Wu et al. found that NMC523 precursors with small primary particle size had largest primary particle size after lithiation, and achieved the best cycling performance. [7] Our results agree with this in that LD shows the most growth in primary particle size and crystallite size, and after $7.5 \mathrm{~h}$ lithiation shows good cyclability. However, VSN, which even as precursor has quite large primary particle size, shows very good cyclability in our results when lithiated for a short time. Increasing lithiation time brings cycling curves of different materials closer together, but the capacity retention of WS 
(a) a-axis according to lithiation time

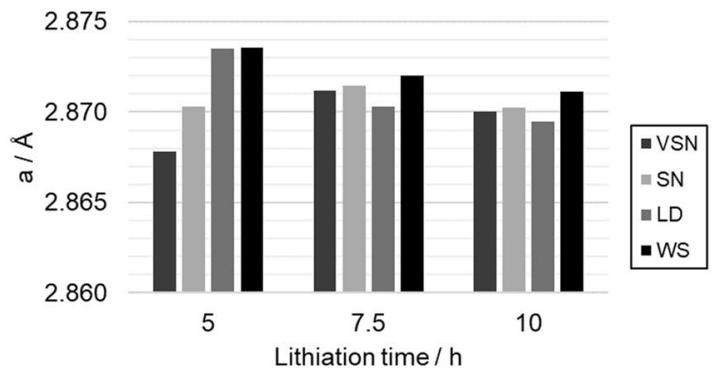

(c)

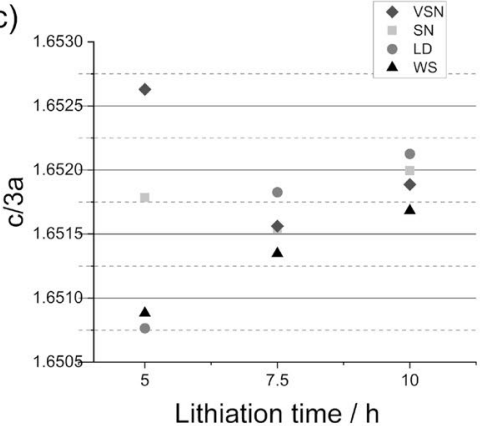

(e) Crystallite size c

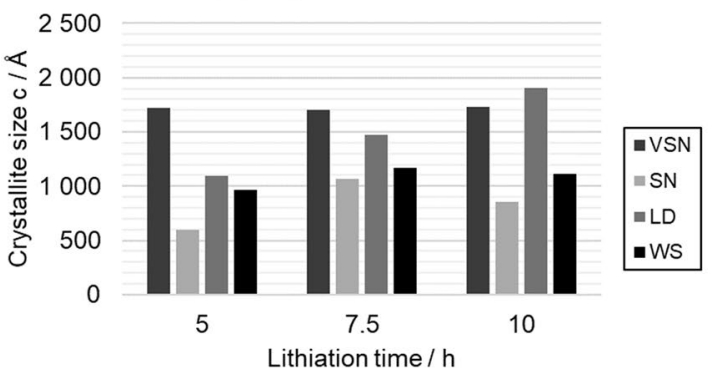

Fig. 4 a Lattice parameter a, b lattice parameter c, and $\mathbf{c}$ ratio of $\mathrm{c} / 3 \mathrm{a}$ for all lithiated and washed materials. $\mathbf{d}$ Ratio of integrated peak area (003)/(104), e the crystallite size along the c-axis and $\mathbf{f}$ the full width

remains lowest, while LD is highest. It was also observed that the first cycle efficiencies (Fig. 7a) become closer as lithiation time increases. The sample with the highest first cycle efficiency is LD lithiated for $7.5 \mathrm{~h}$, though VSN lithiated for $5 \mathrm{~h}$ was very close to it.

\subsection{Effect of precursor on volumetric capacity}

Volumetric capacities of the cathode electrode are shown in Fig. 8. Volumetric capacity has been calculated using the first cycle capacity (C-rate $0.1 \mathrm{C}$ ) of washed sample. Cross section SEM images of cathode electrodes are presented as supplementary data (S7-10). There is a clear (b) c-axis according to lithiation time

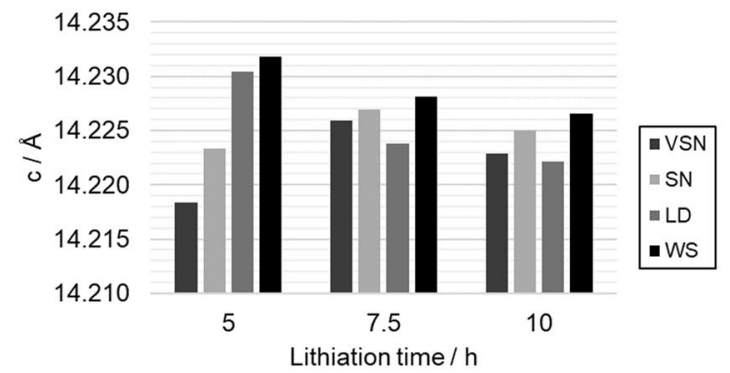

(d) $(003) /(104)$ according to lithiation time

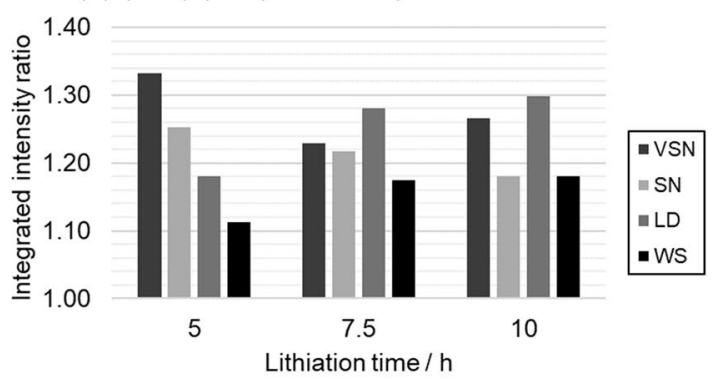

(f) (003) FWHM

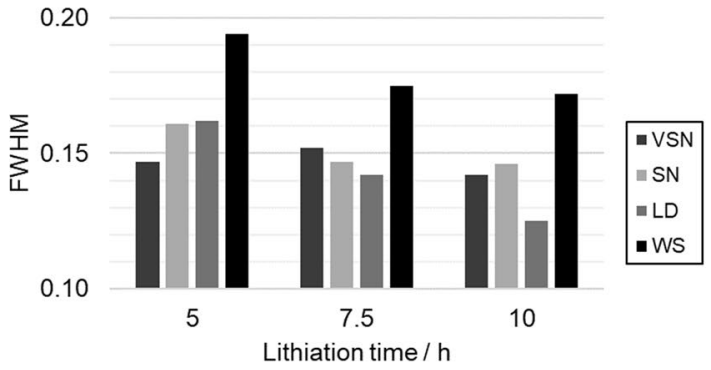

at half maximum (FWHM) of the (003) peak for all lithiated and washed samples as function of lithiation time

difference in the volumetric capacity of the finished electrodes, with WS lithiated for $10 \mathrm{~h}$ having the highest volumetric capacity $\left(503 \mathrm{~mA} \mathrm{~h} \mathrm{~cm}^{-3}\right)$ and VSN lithiated for $10 \mathrm{~h}$ the second highest $\left(484 \mathrm{~mA} \mathrm{~h} \mathrm{~cm}^{-3}\right)$. Based on the SEM images, in the finished cathode electrode the secondary particle morphology of LD has mostly been broken to smaller primary particles. In VSN, SN and WS the particles remain mostly intact, although VSN and SN show some loose primary particles.

The difference in the initial specific capacity achieved by different precursors lithiated for $10 \mathrm{~h}$ was minimal (Fig. 5), so differences in volumetric capacity come from the packing. Comparing the two samples with best volumetric capacity, 

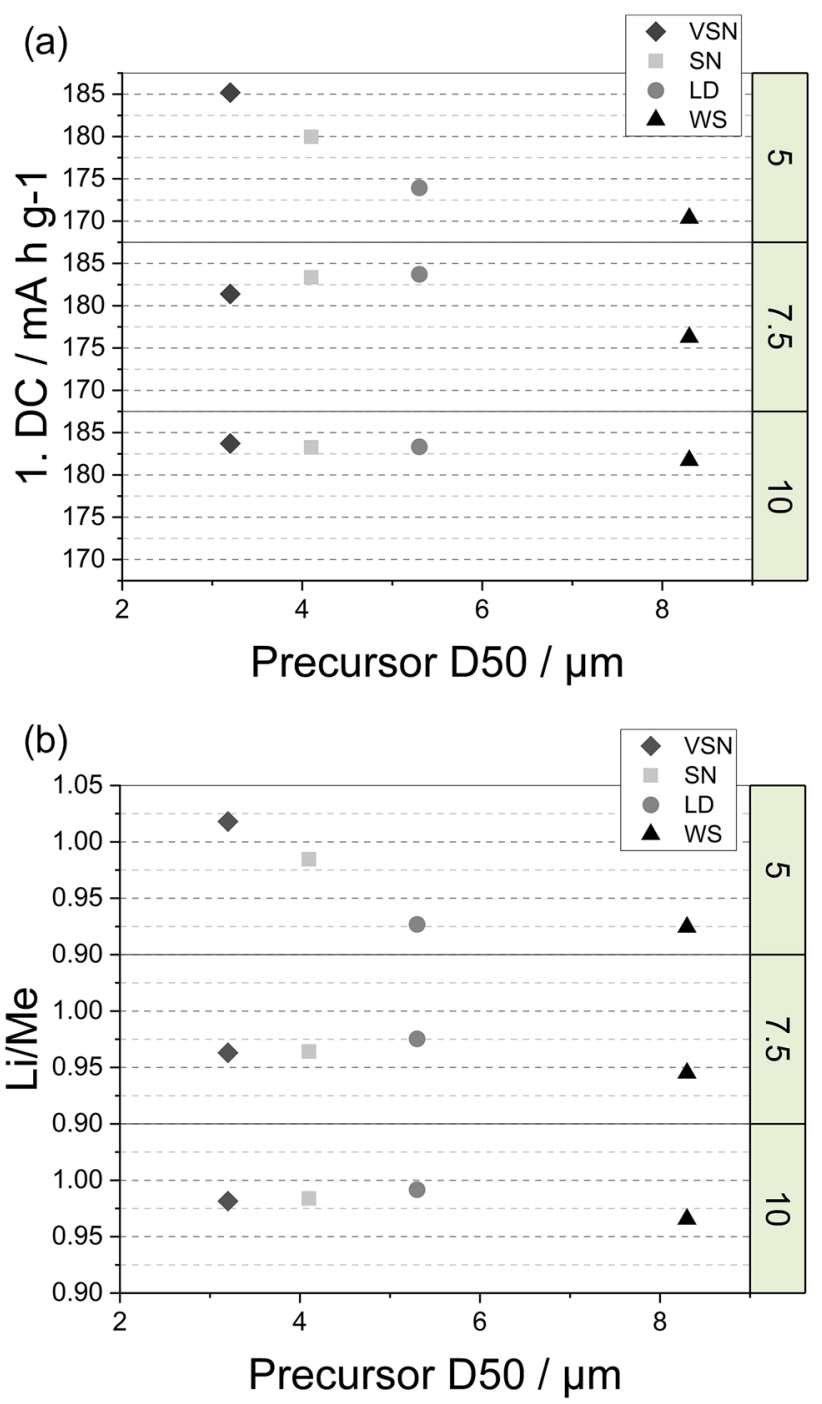

Fig. 5 a The $y$-axis shows the first cycle $(0.1 \mathrm{C})$ discharge current of all lithiated and washed samples. The $\mathrm{x}$-axis indicates the particle size of the precursor. The graph is divided into three parts based on the length of lithiation time $(5 \mathrm{~h}, 7.5 \mathrm{~h}, 10 \mathrm{~h})$. b The y-axis shows mole ratio of lithium divided by the transition metal content measured from lithiated samples after washing. The graph is arranged by precursor particle size and divided into three parts according to the length of lithiation
VSN $10 \mathrm{~h}$ and WS $10 \mathrm{~h}$, their particle fit is quite different (S7-10). In WS the largest particles are significant portion of the cathode electrode width, and the packing is more dependent on particle size distribution, whether there are optimal amount of small particles around to fit in the empty spaces. In VSN the particles are smaller and the empty spaces are smaller, and it might benefit from further calendering pressure. Even though LD seems to be easiest to lithiate fully, it is worst compared to the other precursors when volumetric capacity is considered. The best volumetric capacity was achieved by appropriately lithiating a precursor that already has high packing density. The shorter, and therefore less energy consuming, lithiation time for the small precursors could be taken advantage of by mixing separately lithiated particles of different sizes, as demonstrated by Zhang et al. [19] However, this would remove any benefit of cyclability caused by uniform particle size distribution [20].

\section{Conclusions}

Our results show that there is a clear difference in how quickly the different-sized precursors are lithiated, but there is no significant difference in the initial capacity of products that have been sufficiently lithiated. The results show that the most important factor determining capacity and cycling performance is completeness of lithiation, which has been determined by measuring the ratio of lithium to transition metals after washing. Precursors with larger size require longer lithiation time to achieve complete stoichiometric lithiation. This makes sense if we consider that lithiation must have a certain speed of reaction. Precursors around 3-4 $\mu \mathrm{m}$ in size are well lithiated after $5 \mathrm{~h}$, the $5 \mu \mathrm{m}$ low-density precursor takes $7.5 \mathrm{~h}$ and an $8 \mu \mathrm{m}$ wide-span precursor would likely still benefit from increasing the lithiation time to more than $10 \mathrm{~h}$. The best initial capacity $\left(185 \mathrm{~mA} \mathrm{~h} \mathrm{~g}^{-1}\right)$ and capacity retention ( $93 \%$ for 55 cycles) was seen in the $3 \mu \mathrm{m}$ precursor lithiated for $5 \mathrm{~h}$. C-rate capability of samples correlates with precursor particle size, with smaller particles having better $4 \mathrm{C}$ capacity, although the difference between 
(a) $2 \mathrm{C}$ capacity retention without washing

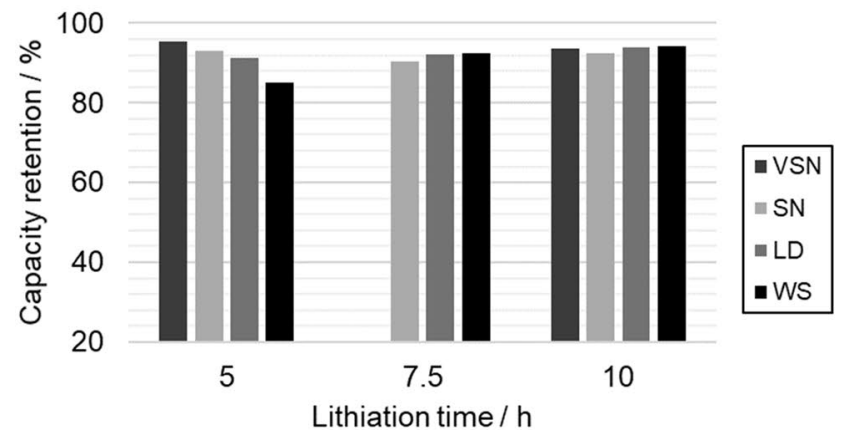

(b) $2 \mathrm{C}$ capacity retention after washing

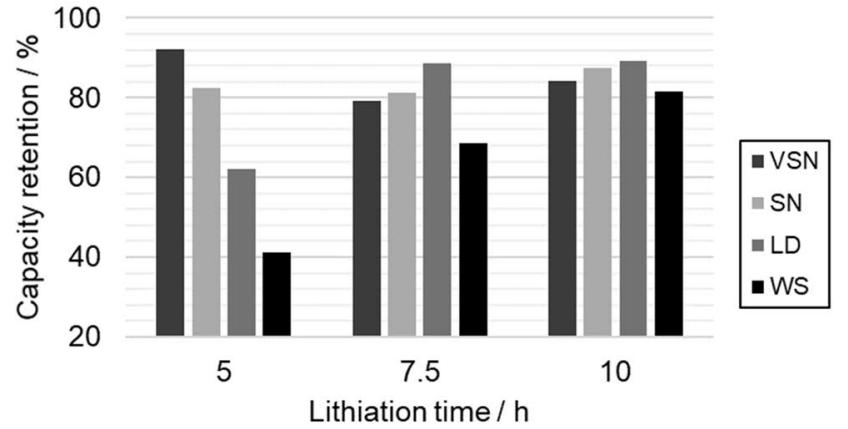

Fig. 6 Capacity retention as a function of lithiation time after cycling at $2 \mathrm{C}$ for 55 cycles. a Capacity retention of unwashed samples and b capacity retention of the same samples that were washed before being made into electrode

$5 \mu \mathrm{m}, 4$ and $3 \mu \mathrm{m}$ particles is minimal. Capacity retention was similar in all samples that were fully lithiated. Washing had the least effect on capacity retention of LD which had achieved the best crystallographic properties.

The effect of precursor on electrode volumetric capacity was also studied. Based on the results, low density of precursor does not lower the capacity $\left(\mathrm{mA} \mathrm{h} \mathrm{g}^{-1}\right)$ if the product is sufficiently lithiated. On the contrary, porous material seems to lithiate closest to the stoichiometric ratio and exhibits a lower amount of cation mixing and the best cycle retention in the 7.5 and $10 \mathrm{~h}$ lithiations. However, their volumetric capacity $\left(\mathrm{mA} \mathrm{h} \mathrm{cm}^{-3}\right)$ will remain lower than materials that have better tap density, as concluded by Cabelguen et al. [4]. This could mean that low-density precursor is good for single-crystal lithiation, in which the lithiated product does not inherit the precursor's morphology. Traditional large widespan material, despite having the lowest amount of lithium in its structure, achieves the best volumetric capacity $(\sim 500$ $\mathrm{mA} \mathrm{h} \mathrm{cm}{ }^{-3}$ ). The very small dense precursor lithiated for

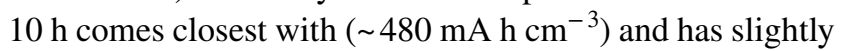
better capacity retention.
Supplementary Information The online version contains supplementary material available at https://doi.org/10.1007/s10800-021-01596-4.

Funding Open access funding provided by University of Oulu including Oulu University Hospital. Authorsacknowledge Business Finland for research funding 2019-2021 (University ofOulu, BATCircle, Dnro $5877 / 31 / 2018)$.

Data Availability Thedata supporting the findings in this article are available within the article.

\section{Declarations}

Conflict of interest Authors have no conflicts of interest to declare.

Open Access This article is licensed under a Creative Commons Attribution 4.0 International License, which permits use, sharing, adaptation, distribution and reproduction in any medium or format, as long as you give appropriate credit to the original author(s) and the source, provide a link to the Creative Commons licence, and indicate if changes were made. The images or other third party material in this article are included in the article's Creative Commons licence, unless indicated otherwise in a credit line to the material. If material is not included in the article's Creative Commons licence and your intended use is not 
Fig. 7 a First cycle coulombic efficiency for all washed samples according to lithiation time. Coin cell cycling profiles for washed samples lithiated for b $5 \mathrm{~h}, \mathbf{c} 7.5 \mathrm{~h}$, and d $10 \mathrm{~h}$. Coin cells were cycled between 3.0 and $4.3 \mathrm{~V}$ at $25^{\circ} \mathrm{C}$. The $\mathrm{C}$-rate varied during cycling as shown in Table 2

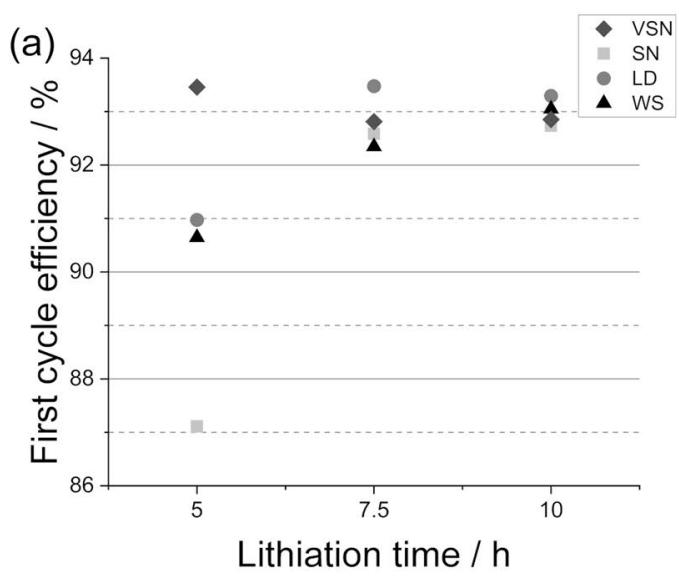

(b) Coin cell cycling of samples lithiated for $5 \mathrm{~h}$

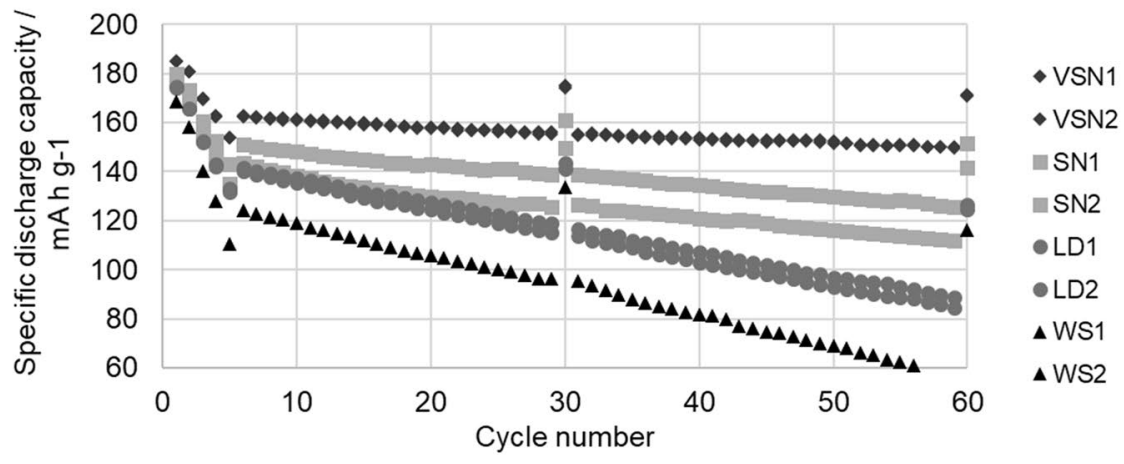

(c) Coin cell cycling of samples lithiated for $7.5 \mathrm{~h}$

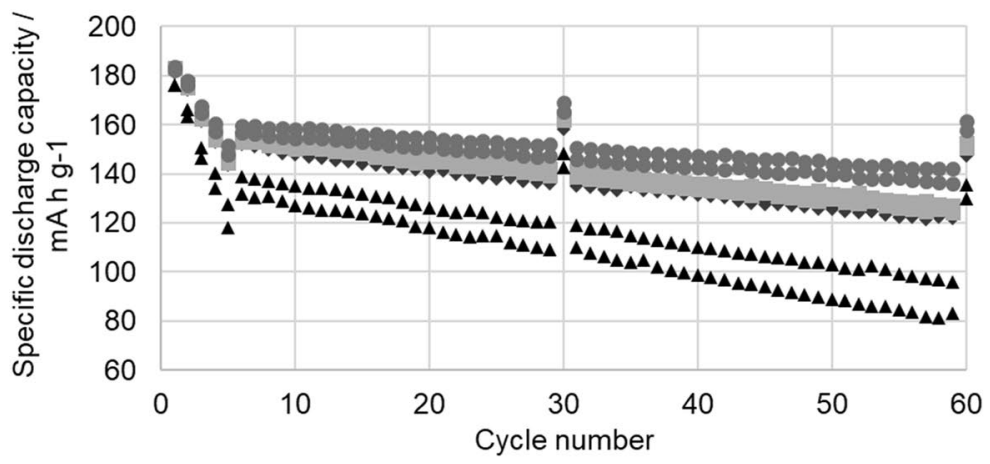

- VSN1

- VSN2

$\square \mathrm{SN} 1$

$\square$ SN2

-LD1

- LD2

$\triangle W S 1$

$\triangle W S 2$

(d) Coin cell cycling of samples lithiated for $10 \mathrm{~h}$

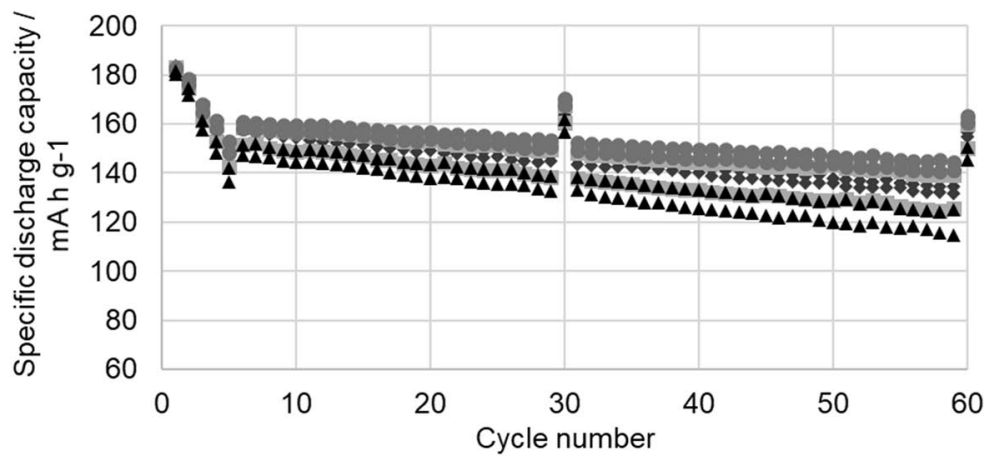

- VSN1

- VSN2

-SN1

- SN2

- LD1

- LD2

$\triangle W S 1$

W W2 


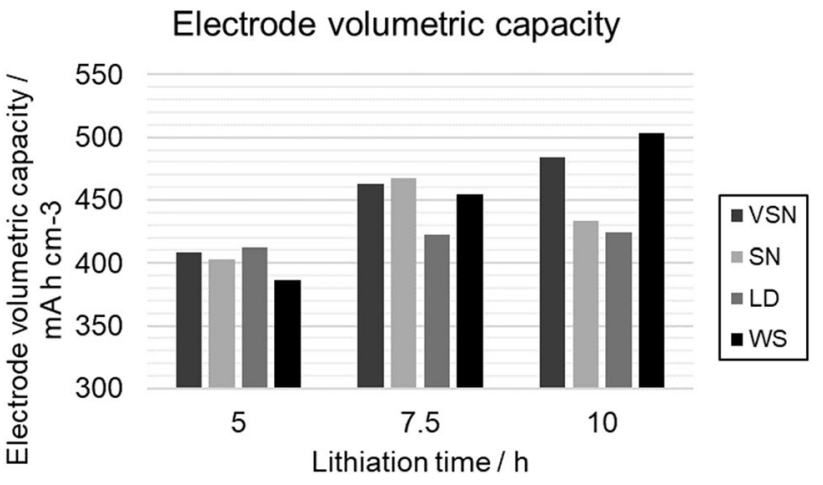

Fig. 8 Electrode volumetric capacity of all washed samples. Energy density is calculated from the first cycle discharge capacity and the weight, thickness, and area of cathode electrode. The weight of the aluminium current collector has been subtracted from the weight of the cathode

permitted by statutory regulation or exceeds the permitted use, you will need to obtain permission directly from the copyright holder. To view a copy of this licence, visit http://creativecommons.org/licenses/by/4.0/.

\section{References}

1. Ohzuku T, Makimura Y (2001) Layered lithium insertion material of $\mathrm{LiCo} 1 / 3 \mathrm{Ni} 1 / 3 \mathrm{Mn} 1 / 3 \mathrm{O} 2$ for lithium-ion batteries. Chem Lett 30:642-643. doi:https://doi.org/10.1246/cl.2001.642

2. Noh H, Youn S, Yoon CS, Sun Y (2013) Comparison of the structural and electrochemical properties of layered $\mathrm{Li}[\mathrm{NixCoyMnz}] \mathrm{O} 2$ $(x=1 / 3,0.5,0.6,0.7,0.8$ and 0.85$)$ cathode material for lithiumion batteries. J Power Sources 233:121-130. doi:https://doi.org/ 10.1016/j.jpowsour.2013.01.063

3. Bak S, Hu E, Zhou Y, Yu X, Senanayake SD, Cho S, Kim K, Chung KY, Yang X, Nam K (2014) Structural changes andthermal stability of charged LiNixMnyCozO2 cathode materials studied bycombined in situ time-resolved XRD and mass spectroscopy. ACS Appl Mater Interfaces 6:22594-22601. https://doi.org/10. 1021/am506712c

4. Cabelguen P, Peralta D, Cugnet M, Maillet P (2017) Impact of morphological changes of $\mathrm{LiNi} 1 / 3 \mathrm{Mn} 1 / 3 \mathrm{Co} 1 / 3 \mathrm{O} 2$ on lithium-ion cathode performances. J Power Sources 346:13-23. doi:https:// doi.org/10.1016/j.jpowsour.2017.02.025

5. Luo X, Wang X, Liao L, Wang X, Gamboa S, Sebastian PJ (2006) Effects of synthesis conditions on the structural and electrochemical properties of layered $\mathrm{Li}[\mathrm{Ni} 1 / 3 \mathrm{Co} 1 / 3 \mathrm{Mn} 1 / 3] \mathrm{O} 2$ cathode material via the hydroxide co-precipitation method. J Power Sources 161:601-605. doi:https://doi.org/10.1016/j. jpowsour.2006.03.090

6. Nie M, Xia Y, Wang Z, Yu F, Zhang Y, Wu J, Wu B (2015) Effects of precursor particle size on the performance of LiNi0.5Co0.2Mn0.3O2 cathode material. Ceram Int 41:1518515192. doi:https://doi.org/10.1016/j.ceramint.2015.08.093

7. Wu K, Wang F, Gao L, Li M-, Xiao L, Zhao L, Hu S, Wang X, Xu Z, Wu Q (2012) Effect of precursor and synthesis temperature on the structural and electrochemical properties of Li(Ni 0.5Co 0.2Mn 0.3)O 2. Electrochim Acta 75:393-398. doi:https://doi.org/10.1016/j.electacta.2012.05.035

8. Bianchini M, Roca-Ayats M, Hartmann P, Brezesinski T, Janek J (2019) There and back again-the journey of LiNiO2 as a cathode active material. Angew Chem Int Ed 58:10434-10458. https://doi.org/10.1002/anie.201812472

9. Wang L, Wu B, Mu D, Liu X, Peng Y, Xu H, Liu Q, Gai L, Wu F (2016) Single-crystal LiNi0.6Co0.2Mn0.2O2 as high performance cathode materials for Li-ion batteries. J Alloys Compd 674:360-367. doi:https://doi.org/10.1016/j.jallcom.2016.03.061

10. Yin S-, Rho Y-, Swainson I, Nazar LF (2006) X-ray/neutron diffraction and electrochemical studies of lithium De/Re-intercalation in Li1-xCo1/3Ni1/3Mn1/3O2( $\mathrm{x}=0 \rightarrow 1)$. Chem Mater 18:1901-1910. https://doi.org/10.1021/cm0511769

11. ZhouC Wang P, Zhang B, Tang L, Tong H, He Z, Zheng J (2019) Formation and effect of residual lithium compounds on Li-rich cathode material Li1.35[Ni0.35Mn0.65]O2. ACS Appl Mater Interfaces 11:11518-11526. https://doi.org/10.1021/ acsami.9b01806

12. Renfrew SE, McCloskey BD (2017) Residual lithiumcarbonate predominantly accounts for first cycle $\mathrm{CO} 2$ and $\mathrm{CO}$ outgassing of Li-stoichiometricand Li-rich layered transition-metal oxides. J Am Chem Soc 139:17853-17860. https://doi.org/10.1021/jacs. $7 \mathrm{~b} 08461$

13. Xu S, Wang X, Zhang W, Xu K, Zhou X, Zhang Y, Wang H, Zhao J (2019) The effects of washing on LiNi 0.83 Co 0.13 Mn 0.04 O 2 cathode materials. Solid State Ion 334:105-110. doi:https://doi.org/10.1016/j.ssi.2019.01.037

14. Azhari L, Zhou X, Sousa B, Yang Z, Gao G, Wang Y (2020) Effects of extended aqueous processing on structure, chemistry, and performance of polycrystalline LiNixMnyCozO2 cathode powders. ACS Appl Mater Interfaces 12:57963-57974. https:// doi.org/10.1021/acsami.0c20105

15. Pritzl D, Teufl T, Freiberg ATS, Strehle B, Sicklinger J, Sommer H, Hartmann P, Gasteiger HA (2019) Editorschoicewashing of nickel-rich cathode materials for lithium-ion batteries:towards a mechanistic understanding. J Electrochem Soc 166:A4056-A4066. https://doi.org/10.1149/2.1351915jes

16. Xiong X, Wang Z, Yue P, Guo H, Wu F, Wang J, Li X (2013) Washing effects on electrochemical performance and storage characteristics of $\mathrm{LiNi} 0.8 \mathrm{Co} 0.1 \mathrm{Mn} 0.1 \mathrm{O} 2$ as cathode material for lithium-ion batteries. J Power Sources 222:318-325. doi:https:// doi.org/10.1016/j.jpowsour.2012.08.029

17. Chen Z, Wang J, Chao D, Baikie T, Bai L, Chen S, Zhao Y, Sum TC, Lin J, Shen Z (2016) Hierarchical porous LiNi1/3Co1/3Mn1/3O2 nano-/micro spherical cathode material: minimized cation mixing and improved $\mathrm{Li}+$ mobility for enhanced electrochemical performance. Sci Rep 6:25771. https:// doi.org/10.1038/srep25771

18. Vu A, Qian Y, Stein A (2012) Porous electrode materials for lithium-ion batteries-how to prepare them and what makes them special. Adv Energy Mater 2:1056-1085. doi:https://doi.org/10. 1002/aenm.201200320

19. Zhang Y, Wang Z, Nie M, Yu F, Xia Y, Liu B, Xue Y, Zheng L, Wu J (2016) A simple method for industrialization to enhance the tap density of $\mathrm{LiNi} 0.5 \mathrm{Co} 0.2 \mathrm{Mn} 0.3 \mathrm{O} 2$ cathode material for high-specific volumetric energy lithium-ion batteries. RSC Adv 6:65941-65949. doi:https://doi.org/10.1039/c6ra11052e

20. Börner M, Horsthemke F, Kollmer F, Haseloff S, Friesen A, Niehoff P, Nowak S, Winter M, Schappacher FM (2016) Degradation effects on the surface of commercial LiNi0.5Co0.2Mn0.3O2 electrodes. J Power Sources 335:45-55. doi:https://doi.org/10.1016/j. jpowsour.2016.09.071

21. Du Z, Wood IIID, Daniel C, Kalnaus S, Li J (2017) Understanding limiting factors in thick electrode performance as applied to high energy density Li-ion batteries. J Appl Electrochem 47:405-415. doi:https://doi.org/10.1007/s10800-017-1047-4

22. Moshtev R, Johnson B (2000) State of the art of commercial Li ion batteries. J Power Sources 91:86-91. doi:https://doi.org/10. 1016/S0378-7753(00)00458-4 
23. Pawley GS (1981) Unit-cell refinement from powder diffraction scans. J Appl Crystallogr 14:357-361. doi:https://doi.org/10.1107/ s0021889881009618

24. Zhu H, Xie T, Chen Z, Li L, Xu M, Wang W, Lai Y, Li J (2014) The impact of vanadium substitution on the structure and elec-

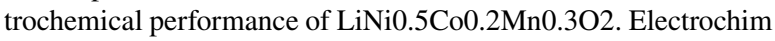
Acta 135:77-85. https://doi.org/10.1016/j.electacta.2014.04.183

25. Cho TH, Park SM, Yoshio M, Hirai T, Hideshima Y (2005) Effect of synthesis condition on the structural and electrochemical properties of $\mathrm{Li}[\mathrm{Ni} 1 / 3 \mathrm{Mn} 1 / 3 \mathrm{Co} 1 / 3] \mathrm{O} 2$ prepared by carbonate co-precipitation method. J Power Sources 142:306-312. doi:https://doi. org/10.1016/j.jpowsour.2004.10.016

26. Whittingham MS (2004) Lithium batteries and cathode materials. Chem Rev 104:4271-4302. https://doi.org/10.1021/cr020731c

27. Dixit M, Kosa M, Lavi OS, Markovsky B, Aurbach D, Major DT (2016) Thermodynamic and kinetic studies of $\mathrm{LiNi} 0.5 \mathrm{Co} 0.2 \mathrm{Mn} 0.3 \mathrm{O} 2$ as a positive electrode material for $\mathrm{Li}$-ion batteries using first principles. Phys Chem Chem Phys 18:6799. doi:https://doi.org/10.1039/C5CP07128C
28. Zhang X, Jiang WJ, Mauger A, Qilu, Gendron F, Julien CM (2010) Minimization of the cation mixing in Li1 + x(NMC) 1 - xO2 as cathode material. J Power Sources 195:1292-1301. doi:https://doi.org/10.1016/j.jpowsour.2009.09.029

29. Liu W, Oh P, Liu X, Lee M-, Cho W, Chae S, Kim Y, Cho J (2015) Nickel-rich layered lithium transition-metal oxide for high-energy lithium-ion batteries. Angew Chem Int Ed 54:4440-4457. https:// doi.org/10.1002/anie.201409262

30. Li H, Li J, Ma X, Dahn JR (2018) Synthesis of single crystal LiNi0.6Mn0.2Co0.2O2 with enhanced electrochemical performance for lithium ion batteries. J Electrochem Soc 165:A1038A1045. doi:https://doi.org/10.1149/2.0951805jes

Publisher's Note Springer Nature remains neutral with regard to jurisdictional claims in published maps and institutional affiliations.

\title{
Authors and Affiliations
}

\author{
Marianna Hietaniemi ${ }^{1,2}$ (D) Tao Hu$^{1}$ (D) Juho Välikangas ${ }^{1,2} \cdot J^{\prime}$ Janne Niittykoski ${ }^{3}$ Ulla Lassi ${ }^{1,2}$ (D) \\ Marianna Hietaniemi \\ marianna.hietaniemi@oulu.fi \\ 1 Research Unit of Sustainable Chemistry, University of Oulu, \\ P.O. BOX 4300, FI-90014 Oulu, Finland \\ 2 Unit of Applied Chemistry, University of Jyväskylä, Kokkola \\ University Consortium Chydenius, Talonpojankatu 2B, \\ 67100 Kokkola, Finland \\ 3 Umicore Finland Oy, P.O. BOX 101, 67101 Kokkola, Finland
}

